Gut, 1978, 19, 19-26

\title{
Clinical presentation of patients with 'dyspepsia' Detailed symptomatic study of 360 patients
}

\author{
JANE C. HORROCKS AND F. T. DE DOMBAL \\ From the University of Leeds, Leeds
}

SUMMARY This paper describes the clinical presentation of 360 patients suffering from 'dyspepsia' at the time of their initial visit to two hospitals in Yorkshire. Disease categories studied were cholecystitis, duodenal ulcer, gastric ulcer, gastric cancer, and 'functional' dyspepsia, with at least 50 patients in each category. The findings of this series are contrasted with 'textbook' descriptions of these conditions. Some contrasts are quite surprising - for example, most of the 360 patients claimed that their pain was not aggravated by food. It is suggested that one reason for diagnostic error in this area of medicine is that clinicians have a faulty mental 'database' of information with regard to the presentation of the various diseases concerned.

Moynihan (1905) claimed that most patients who presented with dyspepsia could be correctly diagnosed solely upon the basis of their symptoms. Unfortunately, this is no longer the case: approximately half of all patients with dyspepsia (both in the United Kingdom and elsewhere) emerge from their first contact with a clinician without a firm, accurate diagnosis having been established (Davis and Williams, 1968; Anderson, 1968; Ross and Dutton, 1972; Horrocks and de Dombal, 1975a).

We ourselves have shown that collecting a predefined, detailed, structured symptomatic history leads to the clinician or computer being able to establish a correct diagnosis (on the patient's first visit) in over $80 \%$ of patients (Horrocks and de Dombal, 1975b). However, one prerequisite of any computer-aided system is a comprehensive 'database' of clinical information about a large series of patients. As part of these computer-aided studies (Horrocks and de Dombal, 1975a, b) we therefore collected a database of clinical information about 360 patients presenting with dyspepsia. These clinical data may be of value per se to practising surgeons and physicians, and are described in detail in this paper.

\section{Methods}

PATIENTS

The 360 patients who formed the basis of this study presented either to one of three surgeons at the

Received for publication 21 June 1977
General Infirmary at Leeds or to a medical/surgical clinic at Airedale District General Hospital suffering from 'dyspepsia' between the spring of 1972 and the summer of 1974. (The latter cases from Airedale District General Hospital were studied to exclude the possibility that cases presenting to surgeons at Leeds General Infirmary were in some way unrepresentative of hospital admissions through the county of Yorkshire.) The disease categories considered in this study were five: cholecystitis, duodenal and gastric ulcer, gastric cancer, and 'functional' dyspepsia. In an earlier survey this group of five disease categories accounted for $96.4 \%$ of patients presenting with dyspepsia to the units in question. We were unable to collect a large enough set of data about 'rarer' causes of dyspepsia (such as pancreatic cancer) and hence these rarer diseases are excluded from present consideration.

\section{PROCEDURE}

Cases were studied on a prospective basis, by scrutiny of the patients' case records and in the vast majority of cases by personal interview by one of us (J.C.H.). The series-though not in practice consecutive because of factors such as illness and annual leavewas unselected. The sole criterion for inclusion was the availability of adequate case data from either the patient's first admission to hospital or (more usually) first presentation to the outpatient department. As we have shown elsewhere (Horrocks and de Dombal, 1975a), there is little difference between the two case histories collected in these two situations, 
which are usually separated chronologically by a very short interval.

\section{PROCESSING METHODS}

The symptoms inquired after are listed in Table 1. Data were stored after collection on the disc of a small desk-top computer (a WANG 700C) situated in the General Infirmary at Leeds. No patient's name appeared on the computer file and none of the data held in the computer was attributable to individual patients. The total database of information comprised just under 10000 items of data processed into the form of a conditional probability matrix. Details of this and other processing methods are given elsewhere (Horrocks, 1974).

Table 1 Items of information relating to 'dyspepsia' and associated symptoms sought from each patient

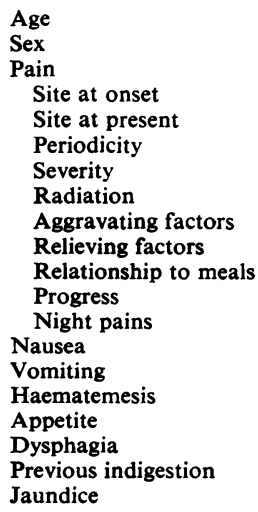

Bowel habit Micturition Weight

Previous surgery Drugs

Family history

Smoking habits Drinking habits

\section{DIAGNOSTIC CRITERIA}

Table 2 shows the composition of this series of patients by sex and disease category. Almost all diagnoses were confirmed at operation. In every case of gastric cancer and cholecystitis, confirmatory histopathological evidence was also available. For many peptic ulcer patients, however, acceptance of visual evidence at laparotomy was necessary (because the standard surgical treatment in Leeds and Airedale for peptic ulcer does not usually involve excision).

There remains a further 'functional' category. As is well known, a proportion of patients initially labelled as 'functional' subsequently prove to have an 'organic' cause for their symptoms (Barfred, 1959; Krag, 1965; Gregory et al., 1972). Hence the placing of patients in this (functional) category should be regarded as a provisional rather than a final diagnosis. However, all patients placed in this category in the present series, in addition to negative radiology, had either (1) negative laparotomy findings, or (2) negative endoscopy findings, or (3) were
Table 2 Disease categories in 360 patients

\begin{tabular}{lllr}
\hline Diagnosis & Male & Female & Total \\
\hline 'Functional' & 23 & 27 & 50 \\
Cholecystitis & 19 & 81 & 100 \\
Duodenal ulcer & 64 & 16 & 80 \\
Gastric ulcer & 34 & 16 & 50 \\
Gastric cancer & 46 & 34 & 80 \\
\hline
\end{tabular}

followed up for up to two years without recurrence of their symptoms.

\section{Results}

\section{AGE AND SEX}

The breakdown of patients by age is shown in Fig. 1 . Some of the data are at variance with textbook descriptions. It is said that the woman with cholecystitis (with or without gallstones) tends to be around the age of 40 years; but $65 \%$ of the women in our series were over 50 years old and $42 \%$ over the age of 60 years. These findings parallel a similar age
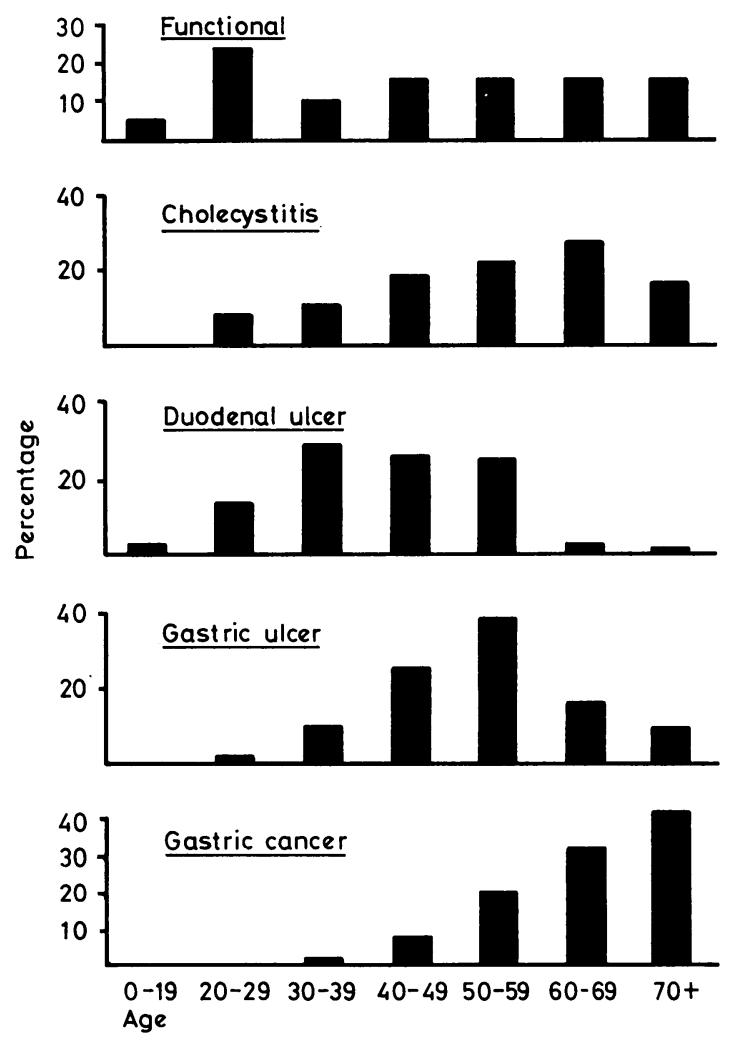

Fig. 1 Composition of series of 360 patients by age. Percentages in Figs. 1-8 indicate proportion of each disease category in relevant age group. 
Table 3 Site of pain in 360 patients with 'dyspepsia'*

\begin{tabular}{|c|c|c|c|c|c|}
\hline & Functional & Cholecystitis & Duodenal ulcer & Gastric ulcer & Gastric cancer \\
\hline RUQ† & 12 & 57 & 9 & 6 & 1 \\
\hline LUQ & 4 & - & 3 & 6 & 5 \\
\hline Upper half & 10 & 15 & 1 & 8 & 6 \\
\hline Lower half & - & - & 4 & 10 & 2 \\
\hline Right half & - & 2 & - & - & 2 \\
\hline Left half & - & 2 & - & - & 2 \\
\hline Central & 4 & 1 & 5 & 2 & 8 \\
\hline General & 4 & - & - & - & 2 \\
\hline Epigastric & 52 & 25 & 86 & 66 & 54 \\
\hline Nil & 16 & - & - & 2 & 19 \\
\hline
\end{tabular}

*Figures in Tables 3-5 are percentages of each group; numbers of patients in each group are shown in Table 2. Some patients had pain in more than one site.

$\dagger$ Right and left upper quadrants.

distribution for acute biliary tract disease (Staniland et al., 1972). Noteworthy are the $16 \%$ of patients with duodenal ulcer who presented before the age of 29 years. Finally, the incidence of carcinoma was higher in the patients who were over 60 years but occasional cases presented in their 40s and we observed one patient under the age of 39 years with proven gastric cancer.

SITE OF PAIN

Most patients (Table 3) suffered from epigastric pain (although just over half of the patients with cholecystitis suffered from pain which was limited to the right upper quadrant of the abdomen). By contrast, $19 \%$ of patients with gastric cancer claimed not to be suffering from pain at or around the time of their hospital interview.

\section{RADIATION OF PAIN}

Inquiry concerning radiation of a patient's pain (Fig. 2) is by no means as 'helpful' as might be imagined. Only $18 \%$ of patients with cholecystitis claimed that their pain radiated to the shoulder. Radiation to the back was more common in cholecystitis than in any other condition; and was more common in 'functional' dyspepsia than in either duodenal ulcer or gastric cancer.

\section{DURATION OF PAIN}

More helpful is the duration of the presenting complaint (Fig. 3). Patients with a short history at presentation to hospital (up to three months) had-in this series of 360 cases-a high risk of having gastric cancer. Moreover, duration of history is a useful discriminant between gastric and duodenal ulcer patients: the majority of the former present to hospital within a year of the onset of their symptoms.

PATTERN OF PAIN

Also helpful in a discriminant sense (Fig. 4) is the pattern of a patient's pain. The majority of patients

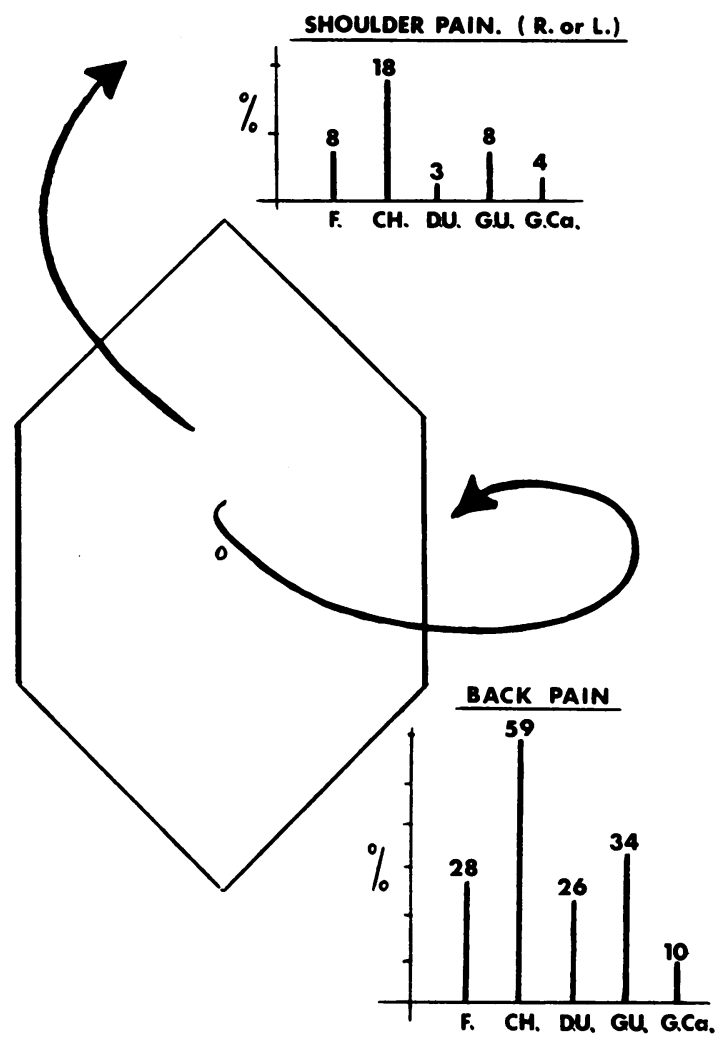

Fig. 2 Radiation of upper abdominal pain in 360 patients with dyspepsia.

who complained of continuous pain suffered from gastric cancer, whereas most patients whose pain came and went in episodes either suffered from duodenal ulcer or were found to have 'functional dyspepsia. ('Episodic' pain was pain presenting in episodes of over two weeks' duration interspersed with remissions of over one month in which the patient was completely free from pain. We dis- 

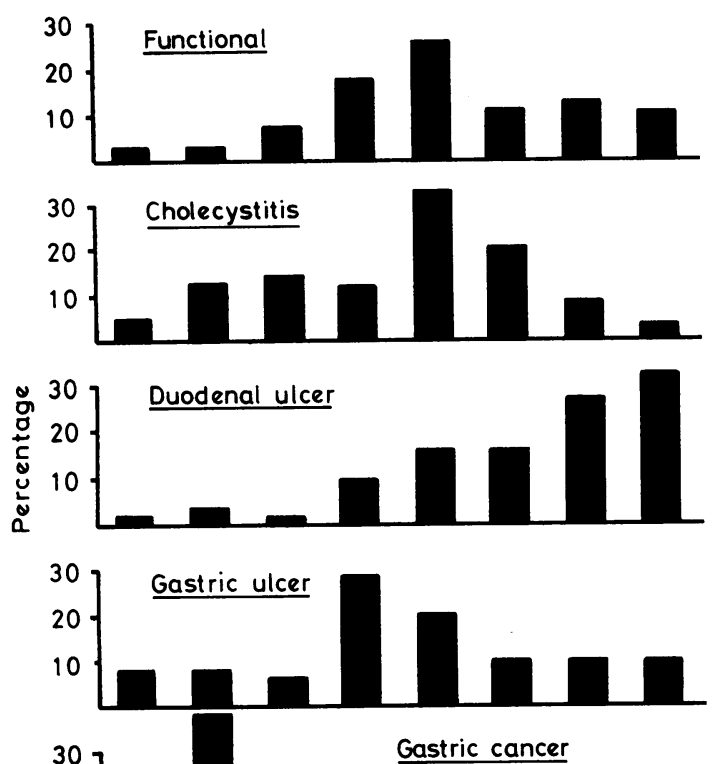

Fig. 3 Duration of presenting complaint in 360 patients surveyed.

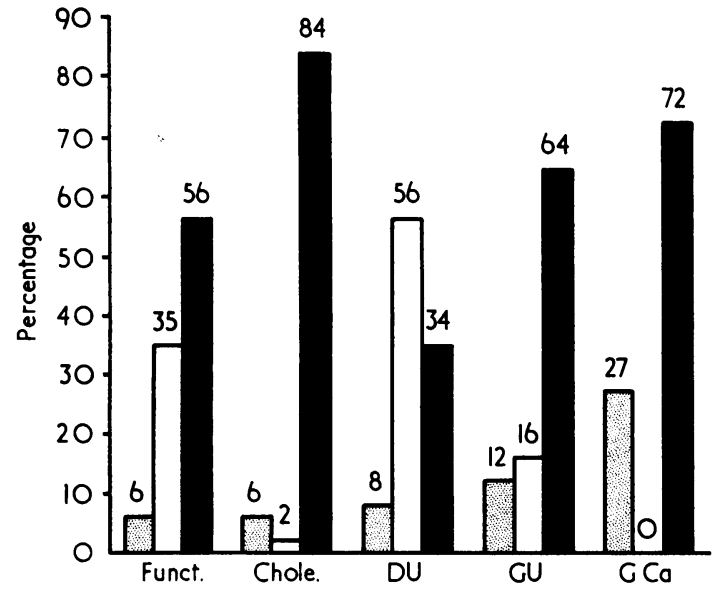

Fig. 4 Pattern of pain in 360 patients with dyspepsia. Continuous pain. $\square$ Episodic pain. Continuing attacks.

tinguish such 'episodic pain' from 'attacks' of pain which are of short duration and may come on at any time.)

As regards severity and progress of pain, little of discriminant value emerged, though $61 \%$ of patients with cholecystitis complained of severe pain (as opposed to around $25 \%$ of patients with peptic ulcer and $19 \%$ of patients with gastric cancer).

\section{AGGRAVATING AND RELIEVING FACTORS}

The majority of patients in this group, in every disease category, claimed that the symptoms which they experienced were unrelated to meals, in the sense that their pain was not aggravated by eating (Fig. 5). Those patients with duodenal ulcer who claimed to have pain made worse by food usually claimed that the exacerbation of pain which they felt was delayed by more than 20 minutes after a meal.

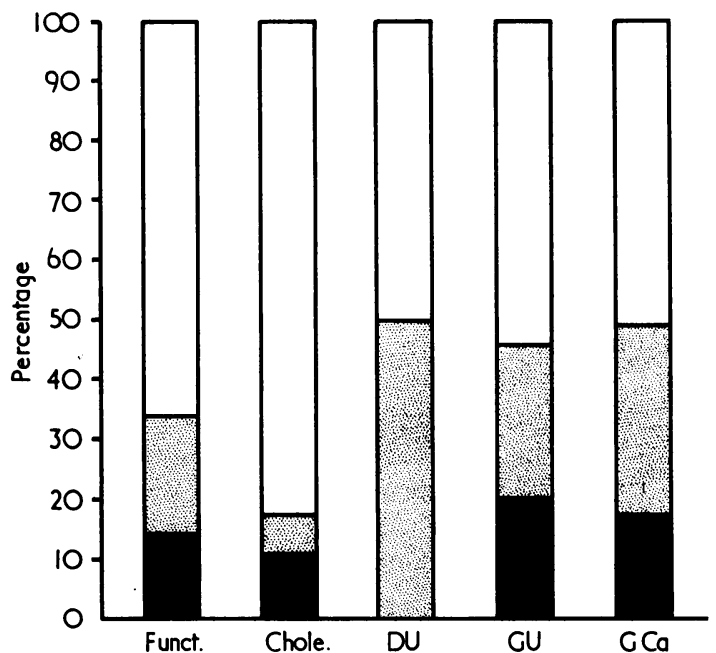

Fig. 5 Relationship of patients' pain to meals. Pain immediately after food. $\square$ Pain delayed after food. Pain not related to food.

As regards relieving factors (Fig. 6), many patients with duodenal ulcer had pain which was relieved by milk, food, and antacids. The 'best' discriminant was food; the patient with gastric ulcer only rarely found relief after eating, whereas $20 \%$ of the patients with duodenal ulcer did so. (This partly confirms one of medicine's oldest adages-that 'the patient with gastric ulcer is afraid to eat and the patient with duodenal ulcer is afraid not to eat'.) There is no evidence from the present study that relief of pain by antacids in any way excludes carcinoma, for $9 \%$ of patients with cancer claimed relief from antacids.

Night pain (pain which woke the patient at night, and not merely pain which happened sometimes to be experienced at that time) was a good discriminant feature (Fig. 7). Seventy per cent of patients with duodenal ulcer claimed that their pain woke them at night. Far fewer patients in any other disease category experienced night pain. 


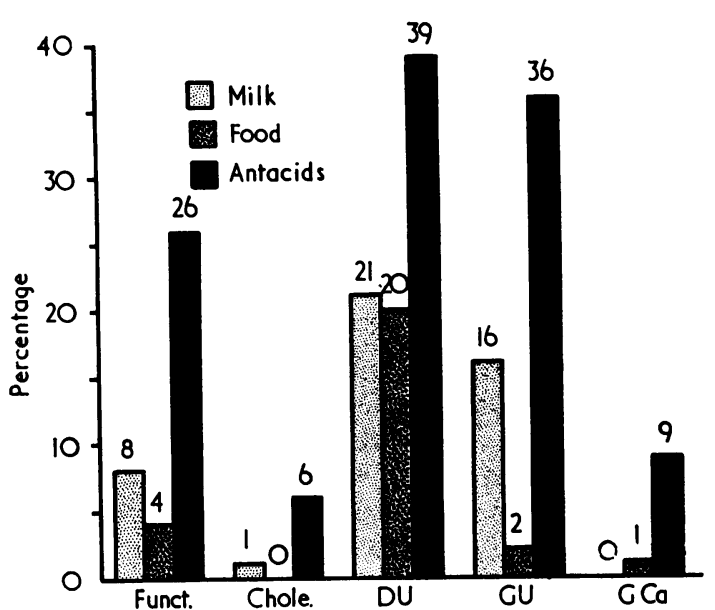

Fig. 6 Factors relieving pain in 360 patients.

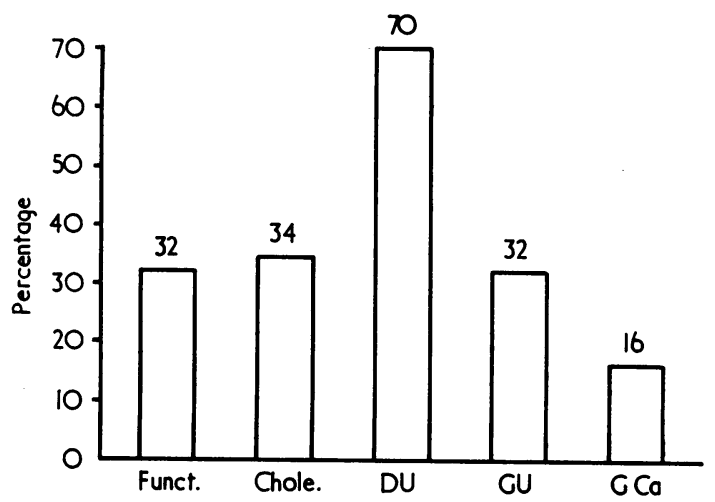

Fig. 7 Proportion of patients in each group with night pain-that is, pain severe enough to wake patient during night.
OTHER UPPER GASTROINTESTINAL SYMPTOMS

Most patients complained of nausea and vomiting (Table 4), but the presence of these two symptoms was of relatively little value in discriminating between disease categories, or, indeed, between organic or functional disorders.

Similarly, although $14 \%$ of patients with peptic ulcer claimed to have had haematemesis at some stage of their disease, so did $5 \%$ of patients with gastric cancer and even $6 \%$ of patients in whom no organic disease was demonstrated. Anorexia was a common finding, but where present rather favoured a diagnosis of carcinoma. Only $10 \%$ of patients with gastric cancer claimed to have a normal appetite at the time at which they were seen. Moreover, just under one in five of the patients with gastric cancer claimed to have some degree of dysphagia (pain on swallowing, plus or minus difficulty in doing so).

Between $25 \%$ and $45 \%$ of patients in each category had suffered from previous indigestion-by which is meant indigestion before the onset of their presenting complaint. Much more useful diagnostically was the presence of jaundice, which was found in around $20 \%$ of patients with cholecystitis, though $4 \%$ of patients with gastric ulcer and $5 \%$ of patients with gastric cancer also complained of (recent) jaundice.

BOWEL HABITS AND MICTURITION

Findings concerning bowel habit are also shown in Table 5. The bowel habit of the majority of patients was normal (as defined by Connellet al., 1965), though constipation was a common finding and more often found in gastric cancer patients than in any other disease category. Pale stools were-as expectedindicative of biliary disease. Melaena, in this series of

Table 4 Symptoms associated with upper gastrointestinal tract in 360 patients with dyspepsia

\begin{tabular}{llllll}
\hline & Functional & Cholecystitis & Duodenal ulcer & Gastric ulcer & Gastric cancer \\
\hline Nausea & 60 & 76 & 59 & 70 & 77 \\
Vomiting & 34 & 66 & 57 & 73 & 66 \\
Haematemesis & 6 & 1 & 36 & 17 & 5 \\
Anorexia & 36 & 1 & 4 & 5 & 90 \\
Dysphagia & 8 & 1 & 5 & 19 \\
\hline
\end{tabular}

Table 5 Bowel habit in 360 patients suffering from dyspepsia*

\begin{tabular}{llllll}
\hline & Functional & Cholecystitis & Duodenal ulcer & Gastric ulcer & Gastric cancer \\
\hline Normal bowels & 82 & 63 & 71 & 66 & 44 \\
Constipation & 10 & 18 & 22 & 16 & 39 \\
Diarrhoea & 2 & 6 & -8 & 7 & 4 \\
Pale stools & 4 & - & 8 & 10 & 14 \\
Malaena & 2 & 15 & & \\
\hline
\end{tabular}

*Figures are percentages of each group of patients. Occasional patients had more than one symptom, for example, diarrhoea and pale stools. 
Table 6 Micturition symptoms in 360 patients suffering from dyspepsia*

\begin{tabular}{llllll}
\hline & Functional & Cholecystitis & Duodenal ulcer & Gastric ulcer & Gastric cancer \\
\hline Normal micturition & 88 & 59 & 71 & 94 & 72 \\
Frequency & 12 & 4 & 4 & 2 & 12 \\
Dysuria & - & 31 & 1 & 2 & 7 \\
Dark urine & - & 4 & 9 & \\
\hline
\end{tabular}

* Occasional patients suffered from one or more symptoms, for example, frequency and dark urine. Figures are percentages of each group with symptom.

patients, was less common in patients with peptic ulcer than gastric cancer. The findings concerning micturition are shown in Table 6.

\section{WEIGHT}

A substantial proportion (Fig. 8) of these patients lost weight (over $7 \mathrm{lb}$ or $3 \mathrm{~kg}$ ) in the weeks before their presentation to hospital. The commonest cause of weight loss was gastric cancer, but $32 \%$ of patients with 'functional' dyspepsia had lost weight also. (Possibly this was due to a concomitant loss of appetite in $36 \%$ of patients with 'functional' dyspepsia.)

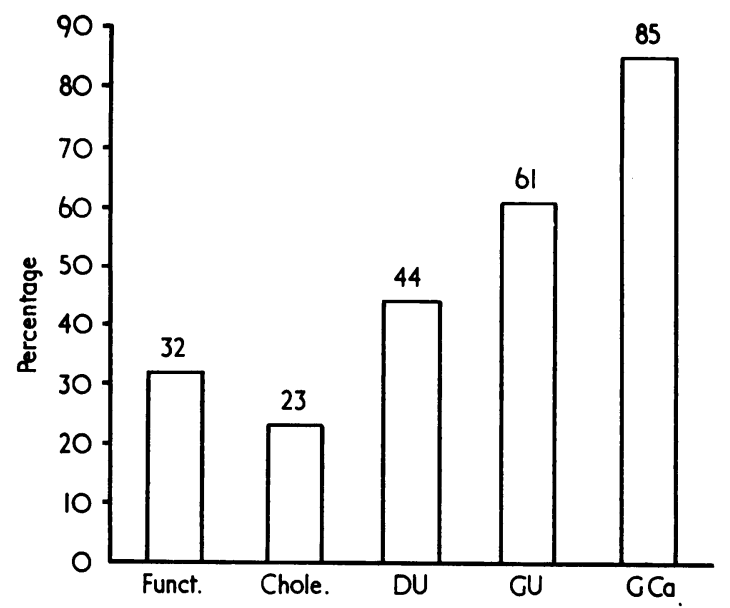

Fig. 8 Proportion of patients in each group with weight loss $>3 \mathrm{~kg}(7 \mathrm{lb})$ in months before admission.

PAST AND SOCIAL HISTORY

Some $25 \%$ to $35 \%$ of patients in each disease category had undergone previous surgery in the abdomen. The majority of patients were taking drugs for relief of symptoms, and this was also of little discriminant value. The presence of a family history was found more commonly with duodenal ulcer patients $(63 \%)$ than any other disease category-though, of the patients with 'functional' dyspepsia, no less than $42 \%$ claimed to have a relative with a similar problem. Cigarette smoking was slightly more common in ulcer patients $(60 \%)$ than other categories.
VARIATION BY GEOGRAPHICAL AREA

Finally, comparisons were made between data from Leeds and Airedale in order to investigate possible variation of presentation by geographical area; and, for further comparison, additional data from a comparable series from Bristol Royal Infirmary (Zoltie et al., 1977) were studied. While there were some geographical variations, the data from the three hospitals were not grossly at odds with one another. Thus, for example, the proportion of patients with duodenal ulcer complaining of pain restricted to the epigastrium was $86 \%$ in Leeds and $78 \%$ in Airedale (though only $60 \%$ in Bristol). For gastric ulcer the comparable figures were $66 \%, 59 \%$, and $69 \%$, and for gastric cancer the proportion of patients ranged from $47 \%$ to $54 \%$. We conclude from this further series of analyses that the data from Leeds are reasonably representative: the point will, however, be further discussed later.

\section{Discussion}

'Though peptic ulcer has been recognised for over 100 years, and affects over $10 \%$ of the entire population, our knowledge of this disease has surprising limitations.' Thus Friedman (1948) bemoaned the lack of hard data on peptic ulcer symptoms. Nearly 30 years later, it remains uncomfortably true that, in recent years, the symptomatology of upper gastrointestinal disease has been to a large extent ignored. Moreover (with the exception of a small number of outstanding studies-for example, Edwards and Coghill, 1968; Scheinok and Rinaldo, 1967; Bouchier et al., 1968; Myren and Serck-Hanssen 1974; Cleator etal., 1973;Earlam, 1976) what literature has appeared has consisted of clinical impression or aphorism rather than observed findings in a large series of patients.

The present study represents an unselected and prospective series; but the patients observed presented to hospital in a Western and largely urban society. Small differences between the series from three different hospitals might tempt us to conclude that the data were representative; but this can be asserted only if we limit ourselves to saying that the data are likely to be representative of hospital admissions in areas culturally similar to the United 
Kingdom. (Indeed, wider geographical variation might well prove a fascinating topic for further study.)

It can also be argued that the data are unrepresentative in that we adopted specific definitions of the symptoms involved. We have, however, tried to define our terminology wherever possible; we have listed these definitions throughout the text and have shown them to have a relatively low observer variation (Horrocks and de Dombal, 1975b).

Having said this, it does appear that in a number of respects the clinical picture of 'dyspepsia' in the medical literature varies from the observed pattern of symptoms in our patients. We shall cite just one example which is both important and typical-the relationship of peptic ulcer pain to food. The pain is said to be 'extremely constant; the pain appears at a definite time after each meal, varying from $\frac{1}{4}$ to $2 \frac{1}{2}$ hours' (Cotton, 1963). Similar definitions occur in a wide variety of textbooks (Elmslie and Ludbrooke, 1971; Taylor et al., 1967).

Unfortunately, our own findings are quite at variance with this 'classical' picture. Less than half of the patients with either duodenal or gastric ulcer complained of pain which was related to meals (in the sense that eating aggravated the pain), while $53 \%$ of the patients we studied claimed that eating did not affect their pain. Moreover, in Scheinok and Rinaldo's (1967) series less than $33 \%$ of the gastric ulcer patients, and under $5 \%$ of the duodenal ulcer patients, claimed that eating made their symptoms worse. Earlam (1976) studying solely duodenal ulcer patients and controls showed similar trends. Finally, in Edwards and Coghill's (1968) study the comparable figures for patients whose pain was associated with food were $24 \%$ for gastric and $10 \%$ for duodenal ulceration.

It is difficult to avoid the conclusion from this series of studies that - at least in the United Kingdom and United States-the 'typical' patient with peptic ulceration does not have pain which is made worse by meals. Though such a relationship is helpful when present, its absence is meaningless in terms of discrimination and diagnosis. One may wonder how long the 'standard' description of these diseases can endure in the textbooks, and it is possible to speculate that one cause of the current difficulty in discriminating between the common causes of dyspepsia is an understandably faulty mental 'database' in the minds of many medical practitioners in some important respects.

Weed (1968) has commented upon the lack of useful information in many current case records throughout the world; and has suggested that for each disease problem there should be a 'database' of relevant information which one routinely obtains from each patient. We ourselves have shown (Horrocks and de Dombal, 1975a, b) that the acquisition of the detailed information contained in Table 1 from each patient with dyspepsia improves clinical diagnostic accuracy by around $20-30 \%$. We suggest that the information detailed in Table 1 might well constitute a 'database' of the type envisaged by Weed, and we recommend that an important step towards more effective diagnosis in dyspepsia should be the 'routine' collation of information of the type outlined in Table 1 from every patient seen.

If this is done, it may again be possible to agree with Moynihan's (1905) assertion 'I am compelled to dissent very confidently from the view that the symptomatic diagnosis of dyspepsia is impossible'.

One of us (J.C.H.) was aided by a grant from the Medical Research Council which we acknowledge with gratitude. We thank also our clinical colleagues who permitted us to study their cases.

\section{References}

Anderson, J. A. D. (1968). Requests for X-Ray examinations from general practitioners and hospital out-patients. Lancet, 2, 97-99.

Barfred, A. (1959). Pseudo-ulcer and true peptic ulcer. Proceedings of the World Congress of Gastroenterology, vol. 1, pp. 352-389. Williams and Wilkins: Baltimore.

Bouchier, I. A. D., Rhodes, K., and Brien, M. (1968). A study of symptomatic and 'silent' gallstone. Scandinavian Journal of Gastroenterology, 3, 299-304.

Cleator, I. G. M., Stoller, J. L., Nunn, P. N., Holubitsky, I. B., Johnstone, F. R. C., and Harrison, R. C. (1973). Discriminant analysis of data in ulcer and non-ulcer populations. American Journal of Digestive Diseases, 18, 301-310.

Connell, A. M., Hilton, C., Irvine, G., Lennard-Jones, J. E., and Misiewicz, J. J. (1965). Variation of bowel habit in two population samples. British Medical Journal, 2, 1095-1099.

Cotton, L. T. (ed.) (1963). Hey Groves' Synopsis of Surgery, p. 476. Wright: Bristol.

Davis, R. H., and Williams, J. E. (1968). X-ray unit for general practitioners. British Medical Journal, 1, 502-504.

Earlam, R. (1976). A computerized questionnaire analysis of duodenal ulcer symtoms. Gastroenterology, 71, 314-317.

Edwards, F. C., and Coghill, N. F. (1968). Clinical manifestations in patients with chronic atrophic gastritis, gastric ulcer and duodenal ulcer. Quarterly Journal of Medicine (New Series), 37, 337-360.

Elmslie, R. G., and Ludbrooke, J. (1971). An Introduction to Surgery, p. 85. Heinemann: London.

Friedman, M. H. (1948). Peptic ulcer and functional dyspepsia in the armed forces. Gastroenterology, 10, 586-606.

Gregory, D. W., Davies, G. T., Evans, K. T., and Rhodes, J. (1972). Natural history of patients with X-ray negative dyspepsia in general practice. British Medical Journal, 4, 519-522.

Horrocks, Jane C. (1974). A computer-aided diagnostic system using a small desk-top computer-calculator. Methods of Information in Medicine, 13, 83-88.

Horrocks, Jane C., and de Dombal, F. T. (1975a). Diagnosis of dyspepsia using data collected by a 'physician's assistant'. British Medical Journal, 2, 421-423.

Horrocks, Jane C., and de Dombal, F. T. (1975b). Computer- 
aided diagnosis of 'dyspepsia'. American Journal of Digestive Diseases, 20, 397-407.

Krag, E. (1965). Pseudo-ulcer and true ulcer. A clinical, radiographic and statistical follow-up study. Acta Medica Scandinavica, 178, 713-728.

Moynihan, B. G. A. (1905). On duodenal ulcer: with notes of 52 operations. Lancet, 1, 340-346.

Myren, J., and Serck-Hanssen, A. (1974). Gastroscopic biopsies in gastric disease: a comparative study with $x$-ray, gastroscopy and clinical evaluation. Acta Pathologica et Microbiologica Scandinavica, Sect. A. suppl. 248. 137-144.

Ross, P., and Dutton, A. M. (1972). Computer analysis of symptom complexes in patients having upper gastrointestinal examinations. American Journal of Digestive Diseases, 17, 248-254.

Scheinok, P. A., and Rinaldo, J. A., Jr (1967). Symptom diagnosis optimal subsets for upper abdominal pain. Computer and Biomedical Research, 1, 221-236.

Staniland, J. R., Ditchburn, Janet C., and de Dombal, F. T. (1972). Clinical presentation of acute abdomen: study of 600 cases. British Medical Journal, 3, 393-398.

Taylor, S., Cotton, L. T., and Murray, J. G. (1967). Short Textbook of Surgery, p. 266. English University Press: London.

Weed, L. L. (1968). Medical Records that guide and teach. New England Journal of Medicine, 278, 593-600.

Zoltie, N., Horrocks, Jane C., and de Dombal, F. T. (1977). Computer-assisted diagnosis of dyspepsia-reports on transferability of a system with emphasis on early diagnosis of gastric cancer. Methods of Information in Medicine, 16, 89-93. 